\title{
Harmonic Structure Design: A Strategy for Outstanding Mechanical Properties in Structural Materials
}

\author{
Bhupendra Sharma $^{1, * \mathbb{D}}$, Guy Dirras ${ }^{2}$ and Kei Ameyama ${ }^{3}$ \\ 1 Department of Mechanical Engineering, Research Organization of Science and Technology, \\ Ritsumeikan University, 1-1-1 Noji-Higashi, Kusatsu 525-8577, Shiga, Japan \\ 2 Universite Sorbonne Paris Nord, LSPM-CNRS, 99 Avenue Jean-Baptiste Clément, 93430 Villetaneuse, France; \\ dirras@univ-paris13.fr \\ 3 Faculty of Science and Engineering, Ritsumeikan University, 1-1-1 Noji-Higashi, Kusatsu 525-8577, Shiga, \\ Japan; ameyama@se.ritsumei.ac.jp \\ * Correspondence: bhupen@fc.ritsumei.ac.jp; Tel.: +81-80-7793-0128
}

Received: 6 October 2020; Accepted: 28 November 2020; Published: 1 December 2020

\begin{abstract}
Structured heterogeneous materials are ubiquitous in a biological system and are now adopted in structural engineering to achieve tailor-made properties in metallic materials. The present paper is an overview of the unique network type heterogeneous structure called Harmonic Structure (HS) consisting of a continuous three-dimensional network of strong ultrafine-grained (shell) skeleton filled with islands of soft coarse-grained (core) zones. The HS microstructure is realized by the strategic processing method involving severe plastic deformation (SPD) of micron-sized metallic powder particles and their subsequent sintering. The microstructure and properties of HS-designed materials can be controlled by altering a fraction of core and shell zones by controlling mechanical milling and sintering conditions depending on the inherent characteristics of a material. The HS-designed metallic materials exhibit an exceptional combination of high strength and ductility, resulting from optimized hierarchical features in the microstructure matrix. The experimental and numerical results demonstrate that the continuous network of gradient structure in addition to the large degree of microstructural heterogeneity leads to obvious mechanical incompatibility and strain partitioning, during plastic deformation. Therefore, in contrast to the conventional homogeneous (homo) structured materials, synergy effects, such as synergy strengthening, can be obtained in HS-designed materials. This review highlights recent developments in HS-structured materials as well as identifies further challenges and opportunities.
\end{abstract}

Keywords: powder metallurgy; harmonic structure; severe plastic deformation; strength-ductility; structural characteristics

\section{Introduction}

Metallic materials are significantly crucial for manufacturing industry and structural applications. Metals with an optimized balance of higher strength and ductility are in demand for many industrial applications. Unfortunately, strength and ductility are antinomies in conventional homogeneous materials. Over many years, ultrafine-grained (UFG) metallic materials proved to be attractive structural materials due to higher strength [1-3], especially when compared to their coarse-grained (CG) counterparts. However, the drawback of homo UFG materials is typically a poor elongation due to the lack of sustained strain hardening rate in the early stage of deformation $[4,5]$. A major challenge, therefore, is to engineer novel microstructures to obtain materials with high synergetic strength and ductility. Therefore, recently, new fabrication and subsequent processing approaches were introduced 
to achieve overall as well as nano-scale microstructural control via grain engineering. One can now create ultrafine-grained homo and heterostructures in metallic materials. The strength and ductility trade-off became a primary challenge in developing high-performance metallic materials.

There have been several successful research studies to achieve high strength while retaining reasonable ductility through solid solution strengthening, precipitation strengthening, transformation hardening, dispersion hardening, etc., by incorporating multiple phases in alloys with several elements, as well as developing composites [6-10]. In addition, several techniques were used to refine the microstructures and improve the mechanical properties through grain refinement by several means, for example; severe plastic deformation, thermo-mechanical treatments, friction stir processing, etc. These techniques use the interruption in the dislocations' motion, but still make a dislocation activity possible to ensure some ductility. It was also reported that using a combination of the above-mentioned approaches, i.e., compositional change and thermomechanical treatment can be used to achieve balanced mechanical properties [11,12]. The focus of this review is, however, on single-phase metallic materials, such as; pure metals (Ti and Ni) or solid solutions (SUS316L) based on principal elements.

\section{The Strength-Ductility Behavior of Homo- and Hetero-Structured Materials}

For the conventional UFG homo metallic materials, the slope of the engineering stress-strain curve after the yield point, i.e., during work hardening, is remarkably lower than that of the counterpart materials with comparatively coarse grains. Figure 1 depicts a schematic drawing of a true stress-true strain diagram of conventional homo-structured metallic materials. It is well known that, during the tensile deformation, the localized reduction in the cross-sectional area of the tensile specimen, i.e., necking, occurs when the rate of strain hardening is lower than the flow stress of the material. It can be expressed as $\mathrm{d} \sigma / \mathrm{d} \varepsilon \leq \sigma$ ( $\sigma$ is the true stress and $\varepsilon$ is the true strain).

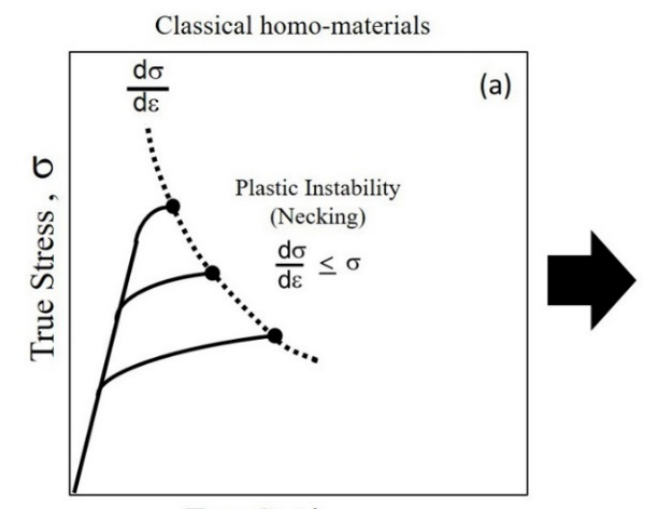

True Strain, $\varepsilon$

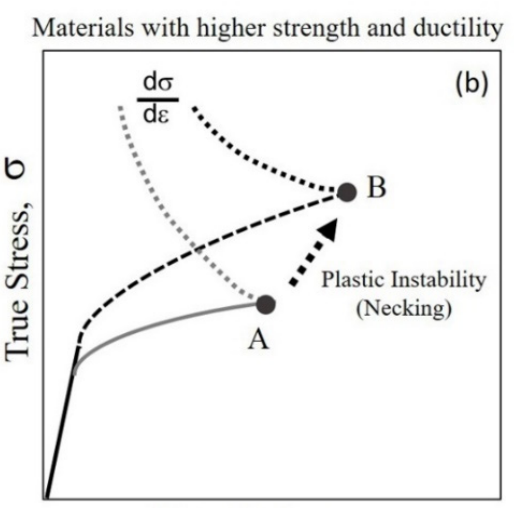

True Strain, $\varepsilon$

Figure 1. Schematic illustrations of true stress-true strain curves in; (a) materials with conventional homogeneous microstructure, and (b) advanced materials with a combination of higher strength and ductility.

In general, high strength but poor ductility of the metallic materials with microstructural homogeneity and fine grains is due to the poor strain hardening capabilities (Figure 1a). However, by introducing heterogeneities in the microstructure matrix, the strain hardening rate $\mathrm{d} \sigma / \mathrm{d} \varepsilon$ of the metallic materials can be improved while preventing the inequality conditions (Figure 1b). In other words, a good combination of superior strength and ductility can be achieved when a larger strain hardening rate is achieved. In addition, at the same time, deformation localization should be suppressed to obtain further elongation.

To address this strength-ductility trade-off issue, heterogeneous structures with large microstructural heterogeneities were introduced in metallic materials [3,13-16], such as bimodal structure [17], gradient structure [18-20], gradient nano-twined structure [21], nano-laminae structure [22], and heterogeneous laminae structure [13]. Such heterogeneous-designed structures 
were prepared via developing modern processing techniques without changing the composition, which includes surface grinding or rolling, severe plastic deformation, and electrodeposition. The resulting structured heterogeneous materials exhibit excellent mechanical properties.

Many pieces of research are being conducted on hetero-structured materials owing to their controllable and superior mechanical properties that are unattainable in the conventional homogeneous-structured materials. Therefore, structured heterogeneous materials are quickly emerging as a major materials research area, which also presents renewed concepts of materials science that challenged our traditional perceptions and impressions. In this review paper, we primarily focus on the microstructural heterogeneities in the metallic materials. Compared to conventional homo materials, hetero-structured metallic materials contain heterogeneous regions that contrast in their constitutive properties. It was reported that structured heterogeneous materials are advantageous properties owing to the synergetic effects occurring from the interactivity and pairing between structural contrasting. For example, the trade-off in strength and ductility can be alleviated or controlled [13-15]. This intended structural contrasting induces heterogeneous plastic deformation, and the fine-scale constituents stipulate exorbitant strain gradients. As a result, higher strain hardening and consequently uniform tensile ductility at high flow stresses can be achieved. However, the realization of heterogeneous design together with their microstructure and properties control is limited by multiple complex processing steps. Nevertheless, their properties are limited to the uni- or bidirectional (anisotropic characteristics).

Recently, Ameyama et al. proposed a novel concept of "harmonic structure" (HS) design, consisting of a specific spatial distribution of ultra-fine grains (UFG) and coarse grains (CG), that is, the CG areas (core) surrounded by three-dimensionally (3D) continuously connected network of UFG areas (shell) [23-31]. Owing to its unique topological 3D gradient structure, the harmonic-structured materials were reported to exhibit high work hardening that extends to higher strain regions, leading to delay in the initiation of plastic instability. Consequently, a good combination of high strength and high ductility can be achieved [29-31].

In the present review, an overview of the basics of harmonic structure design and highlighting recent developments in harmonic structured materials is presented, as well as identifying perspectives and future challenges and opportunities.

\section{Concept of Harmonic Structure Design and Processing Considerations}

From the above points, the harmonic structure (HS) design can be a candidate material design, which combines high strength with high ductility at the same time. Figure 2 demonstrates a concept of the HS design. The HS material is composed of a shell/core bimodal particle unit. A harmonic structure designed material is produced by the sintering of the particle units. In contrast to a homo-UFG material, HS material has a heterogeneous microstructure consisting of controlled and uniquely arranged fine and coarse grains with a particular topological distribution in a network. That is, the HS can be visualized as homogeneous on large scale but heterogeneous on a small scale, as shown in Figure 2.

During fabrication processing, it is crucial to control and optimize the characteristics of the shell/core regions, such as; volume fraction, grain size, morphology, and topology. These characteristics may strongly influence the properties of the HS materials. The physical properties of the HS materials can be affected by the grain size distribution and grain gradients and morphology of the shell/core regions. To control these factors in the as-fabricated HS compacts, it is necessary but challenging to invent efficient processing methods. In this regard, the unique three-dimensional network-type microstructure of the HS materials adds considerable complexity to processing. In addition to the wide range of multiple variables, the type of material, i.e., the behavior of a particular class of materials, also affects the microstructure of the as-fabricated HS compacts. However, in general, by varying these parameters, HS microstructure was developed in various metals and alloys. To achieve a tailor-made HS microstructure design, the following efficient and feasible processing method, based on powder metallurgy processing, was developed. 


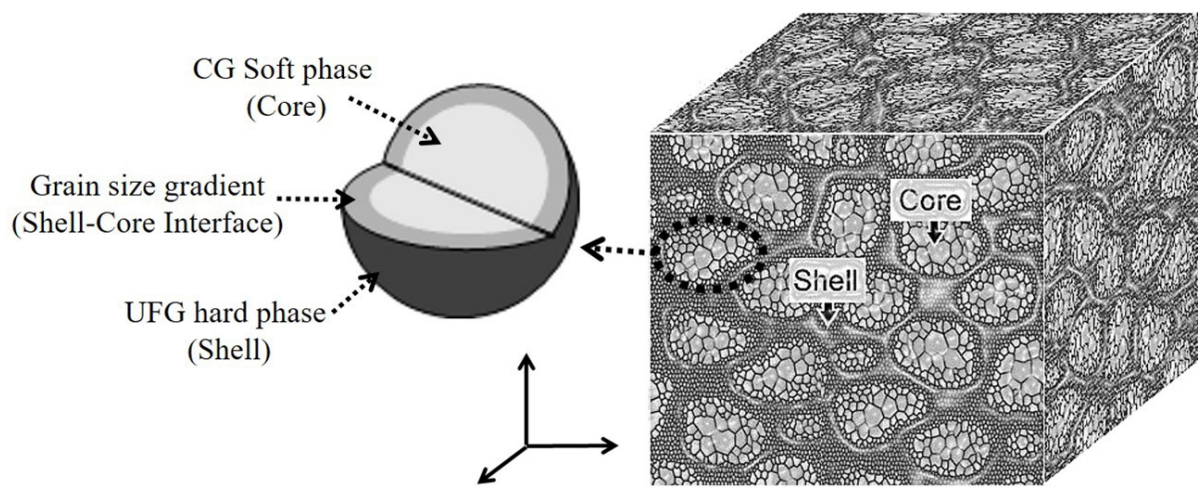

Figure 2. Concept of the harmonic structure (HS) design.

\subsection{Mechanical Milling Process (MM Process)}

The MM process involves mechanical milling (i.e., ball milling, high-pressure gas milling, etc.) of Plasma Rotating Electrode Processed (PREP) powder of metallic powder and their subsequent sintering. As shown in Figure 3a, powder with a bimodal grain size distribution, i.e., SPD powder surface with fine grains (shell), and comparatively less deformed (or undeformed) powder interior (core), can be fabricated by the MM process. The MM processed powder surface becomes the three-dimensional shell network structure after sintering. As depicted in the schematic diagram of Figure 3a, the depth of plastic deformation, at the powder surface, can be changed by changing the mechanical milling time. Consequently, it is feasible to achieve a tailor-made microstructure with predetermined shell/core fractions. However, it is to be noted that the deformation at the surface and respective microstructure evolution depends on the type of initial material.

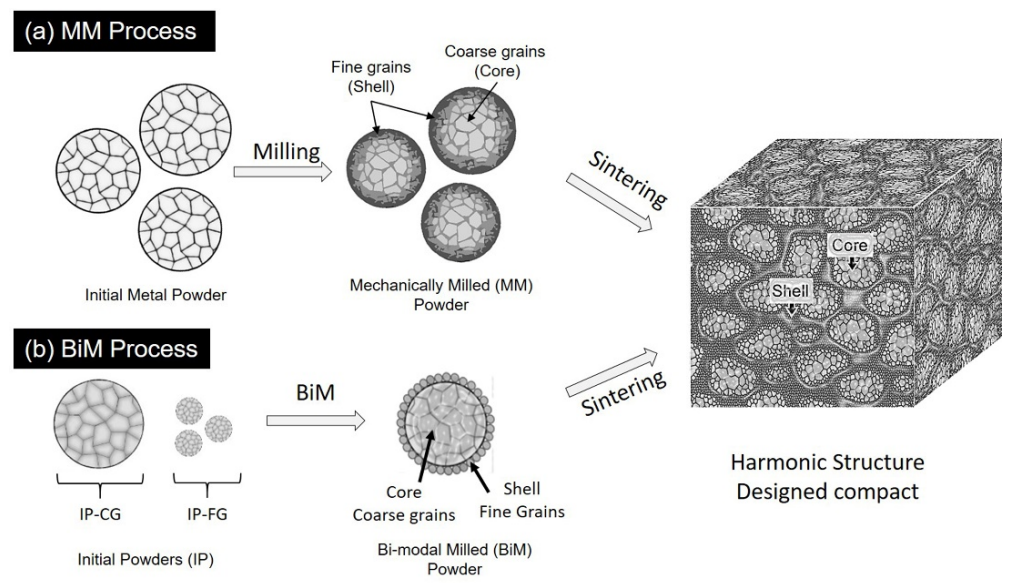

Figure 3. Fabrication processes of the harmonic structure materials; (a) Mechanical Milling (MM) and (b) Bimodal Milling (BiM) process.

\subsection{Bimodal Milling Process (BiM Process)}

The BiM process involves milling initial powders of coarse-grained large-sized (IP-CG) and comparatively fine-grained small-sized (IP-FG) powders, wherein the powder fractions and milling time are chosen depending on the desired fractions and grain size of shell/core, respectively [32]. The hierarchical distribution of fine/coarse-grains can be achieved due to repeated coating of plastically deformed IP-FG to the IP-CG powder, during milling. A schematic diagram illustrating the BiM powder metallurgy-based processing approach is demonstrated in Figure $3 \mathrm{~b}$. As depicted in the schematic diagram of Figure $3 b$, the fraction of a tailor-made microstructure with desired shell/core fractions can be achieved either by varying the fractions of IP-FG and IP-CG powders, and/or varying milling time. 
The selection of a specific fabrication process was based on many factors such as the type of material, powder particles size, the susceptibility of the material with milling media, the permitted level of contamination from the milling vial and balls, and malleability and work hardening characteristics of the materials being processed [27]. For example, the soft materials can be flattened, i.e., might form flakes, during the severe milling process. Therefore, the BiM processing approach can be utilized to achieve a high shell fraction in a short time milling. On the other hand, less ductile materials can be processed through the MM process.

\section{Microstructure of BiM and MM Processed Powders}

The effect of controlled milling through BiM and MM processes on the morphology and microstructure of SUS316L alloys powders is shown in Figure 4. In the BiM process, IP-FG (powder particle size $\sim 7 \mu \mathrm{m}$ ) and IP-CG (powder particle size $\sim 142 \mu \mathrm{m}$ ) powders were mixed in a 3:2 ratio, respectively, and BiM processed for 36 and $360 \mathrm{ks}$ (Figure 4a,b). On the other hand, in the MM process, the PREP alloy powder of SUS316L IP-CG was milled for 108 and $540 \mathrm{ks.}$
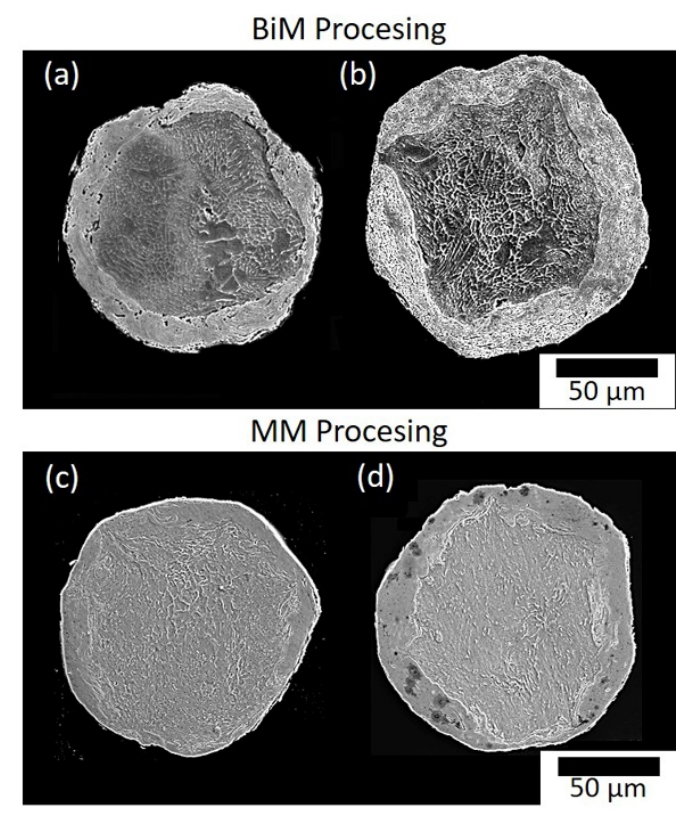

Figure 4. SEM images of SUS316L powders cross-section after BiM and MM processing. (a) BiM $36 \mathrm{ks,}$ (b) BiM 360 ks, (c) MM 108 ks, and (d) MM 540 ks.

It is evident that the overall morphology of the spherical shape of the powder does not change as a result of both $\mathrm{MM}$ and BiM processing. However, it is to be noted that a highly deformed zone (shell) is formed at the surface, whereas the inner regions (Core) of the powder remain approximately undeformed or partially deformed, depending on the milling conditions. It is interesting to note that the high fraction of shell could be achieved in a shorter time of BiM processing compared to the MM processing. In contrast to the MM powder, the outer surface of BiM powder is composed of several layers of fine powder particles.

Therefore, it can be predicted that the shell evolution mechanism in both BiM and MM process is different. It was reported that the powder particle size of BiM powders increases with BiM processing time, whereas in the case of the MM process, the MM powder particle size remains approximately similar to the starting powder. Therefore, it can be assumed that the surface irregularity of the BiM powder is primarily due to the repeated coating of SPD fine powder to the surface of coarse powder, during milling. On the other hand, the surface irregularity in MM powder is owing to the surface deformation of the starting powder particles. However, it can be ensured that both $\mathrm{MM}$ and BiM powders show a bimodal microstructure wherein the center of powder is coarse-grained, whereas 
the surface composed of SPD sub-micron-sized grains. Similar morphological changes were also reported wherein it was observed that the increase in milling time leads to the formation of the severely deformed layer, consisting of nano-crystallites, near the surface of the powders [33-37]. Moreover, it must be realized that a gradient of the degree of deformation exists in both BiM and MM processed powders, and the severity of the accumulated plastic strain decreases from the particle surface towards the center of the particles.

In particular, the successful application of the new BiM process to achieve controlled deformation in the variety of materials is of important technological interest, which is a feasible, energy-efficient, and cost-effective process, particularly, for industrial-scale production. The effectiveness of the BiM process to create a controlled microstructure at shell and core is owing to the fine and coarse powders, respectively. It must be pointed out that the finer powder particles make the milling process easier, and grain refinement occurs in a shorter time when compared to coarse powder particles. Therefore, in contrast to the prolonged milling in the MM process, significantly shorter milling might result in the development of a large shell fraction with nano grain formation. It naturally follows that one can build a hierarchical microstructure with controlled fractions of shell/core zones by varying amounts of IP-FG and IP-CG powders, and/or milling time. Optimizing such hierarchical grained zones and their fractions for a better synergy of superior strength and ductility, in an as-sintered bulk compact, calls for modern fabrication approaches for precise microstructure control. Hence, it would be appealing to analogize the designs of BiM- and MM-processed SUS316L compacts for a better interpretation and rationalization of the synergistic effects of various combinations of structural contrasts.

Figure 5 shows TEM micrographs near the shell region of the mechanically milled pure titanium powder with enlarged areas of selected rectangular areas indicated as A, B, and C. It could be observed that near to the surface, equiaxed grains $(<20 \mathrm{~nm})$ were observed whereas a layer of elongated grains was seen in the inner zones of the milled powder. The grain subdivision and rotation of those elongated grains led to the formation of equiaxed nano-grain structure in milled powder [30,33,37-41].

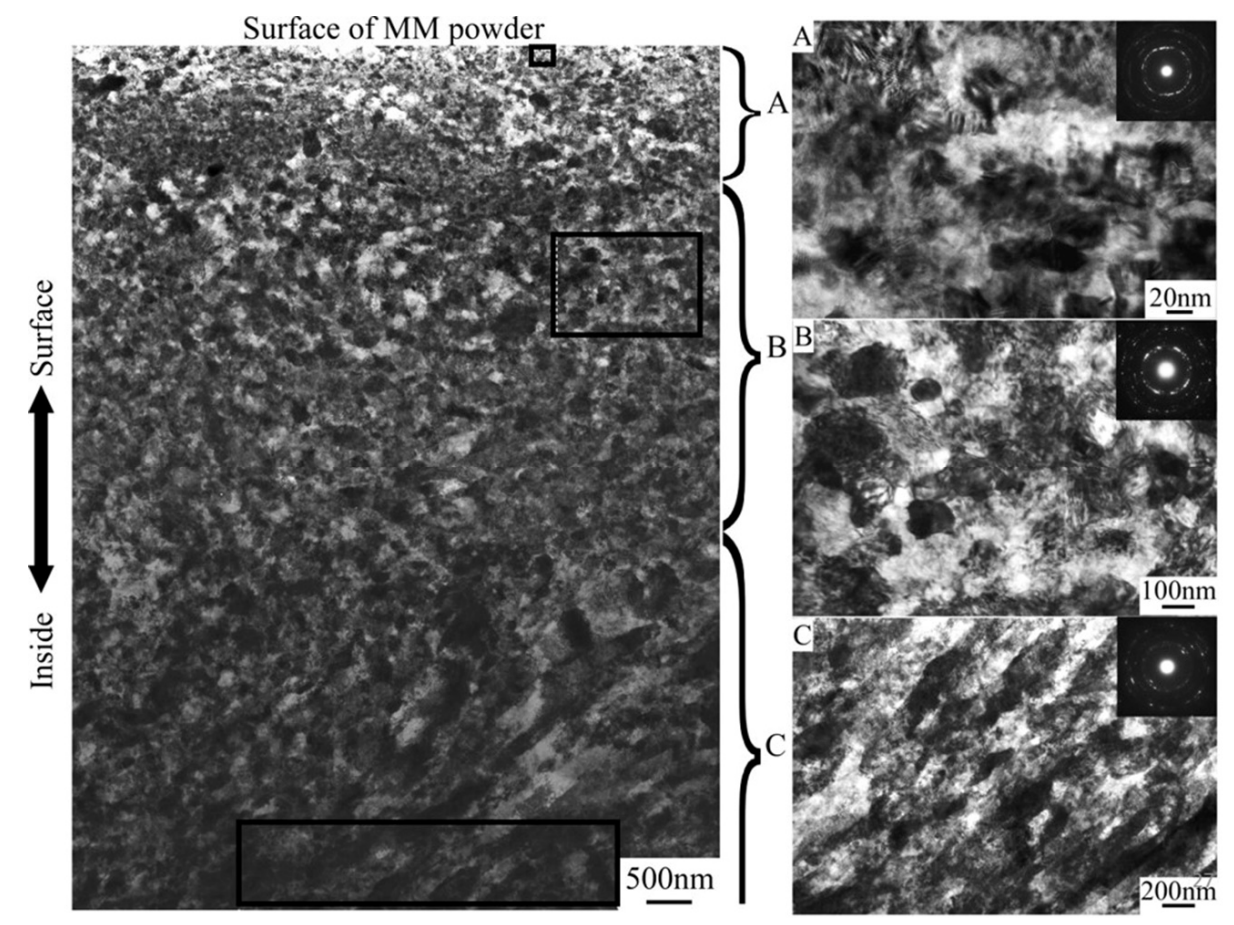

Figure 5. TEM micrographs of the shell area of milled pure Ti powder. Enlargement of rectangular areas of (A), (B) and (C) are separately presented. 


\section{Microstructure of Harmonic Structure Designed Compacts}

The milled powders via the BiM and MM process were sintered at 1173 and $1223 \mathrm{~K}$ temperatures, respectively, to prepare bulk compacts. Recently, spark plasma sintering (SPS) was utilized extensively for the consolidation of powders due to fast sintering together with avoidance of significant grain growth even at high-temperature operations. The microstructures of the H-structured compacts (MM and BiM) SUS316L compacts are shown in Figure 6.

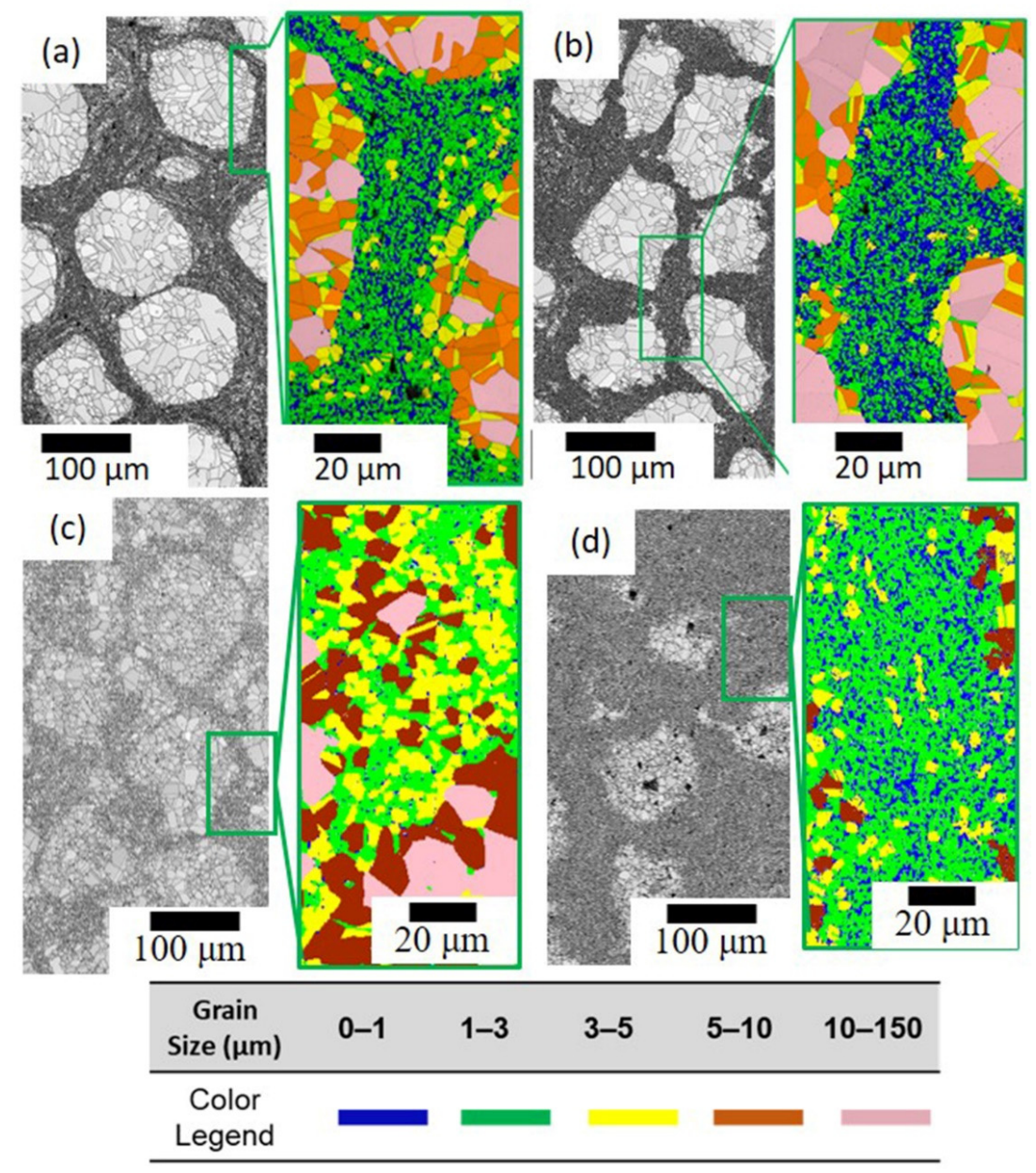

Figure 6. EBSD image quality maps of $\operatorname{BiM}(\mathbf{a}, \mathbf{b})$, and MM compacts (c,d) of SUS316L. (a) BiM $36 \mathrm{ks,}$ (b) BiM 180 ks, (c) MM 216 ks, and (d) MM 540 ks. The corresponding enlarged grain size images of the shell-core interface are separately shown (the grain size legend is presented at the bottom).

As shown in Figure 6a,b, the BiM compacts exhibited a network-type arrangement of bimodal grains wherein the coarse grains $(\mathrm{d}>5.0 \mu \mathrm{m})$ were surrounded by comparatively finer grains $(\mathrm{d} \leq 5.0 \mu \mathrm{m})$. Particularly, it is to be noted that the well-defined and dense shell network could be achieved even after a short time ( $36 \mathrm{ks}$ ) of BiM processing (Figure $6 \mathrm{c}$ ). The grain size contrast of the shell and core could be observed in the enlarged Elecrtron Backscatter Diffraction (EBSD) grain size images. It should be noted that the core grains are not remarkably deformed even after a long milling time (180 ks). Therefore, it can be envisaged that the shell area of BiM compacts mainly developed due to the coating and frequent plastic deformation of fine particles to the surface of coarse particles, during milling. However, the spherical shape of the core gradually deformed with milling time, suggesting that the prolonged milling leads to the partial deformation of the outer core area. Therefore, it can be envisaged that increasing milling time leads to effective plastic deformation of fine powder, which in turn increases the fraction of fine shell grains $(<3 \mu \mathrm{m})$, which was obvious in the shell grain size 
distribution through the color-coded grain size distribution map of BiM compacts. Also, in the case of MM compacts (Figure $6 \mathrm{c}, \mathrm{d}$ ), a harmonic structure was achieved. However, substantial damage apparent to the core area was noticed after a long period of milling (540 ks). In addition, most notable was that even after prolonged milling up to $540 \mathrm{ks}$, the large fractions of shell grains were in the range of 3-5 $\mathrm{m}$, which is significantly larger than that of the BiM-processed specimens. Finally, it would be worth emphasizing that, in comparison to the MM process, the BiM approach is highly efficient in achieving ultra-fine shell grains in a shorter period.

\section{Mechanical Properties of Harmonic Structure-Designed Compacts}

Figure 7 shows the representative engineering stress-strain curves of harmonic structured compacts of SUS316L developed by BiM and MM approaches. All of the HS materials that were examined indicated high strength, high ductility, and high tensile toughness at the same time. That is to say, regardless of the fabrication process, the HS compacts of SUS316L had a good combination of strength and elongation compared to the conventional counterparts developed and/or processed by different methods, such as; casting, powder metallurgy, selective laser melting, and thermomechanically treated compacts of SUS316L alloy (Figure 8) [42-61]. In general, it was reported that the conventional homo-structured compacts of SUS316L exhibited significant strength-ductility trade-off owing to the grain size strengthening effect [42-61]. However, in contrast, as shown in Figure 7, the improvement in the strength of harmonic structured SUS316L compacts were accompanied by a nominal ductility loss. The improvement in strength and nominal ductility loss can be attributed to grain boundary strengthening caused by grain refinement in the shell and higher shell fraction. Particularly, the reduction in ductility is associated with a higher shell fraction, as shown in Figure 6. Plastic deformation in most metallic materials was commonly mediated by the dislocation slip [26,27]. The increased fractions of fine-grained shell from a certain level suppressed the dislocation initiation and slip phenomena, and increased the prospect of dislocation annihilation at boundaries by thermally activated cross slip and climb, which in turn leads to ductility loss [28,29]. The most noticeable was the synergy of high strength and ductility of harmonic-structured BiM compacts, which was achieved in an efficient time compared to that achieved by MM processing. As can be seen, the improvement in mechanical properties by efficient BiM processing was encouraging, which may lead to the synergetic strength-ductility combination by introducing an optimized fraction of the shell network. In the present case, the optimized grain size and shell fractions were approximately $2 \mu \mathrm{m}$ and 30\%, respectively [32].

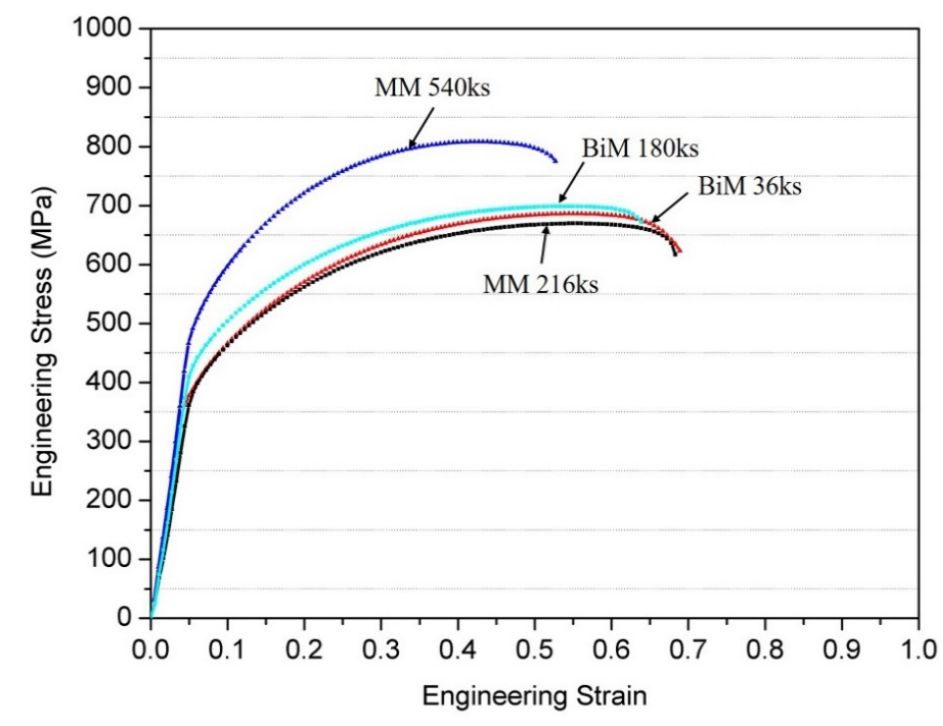

Figure 7. Tensile engineering stress-strain curves of harmonic structured SUS316L compacts developed through BiM and MM processes. 


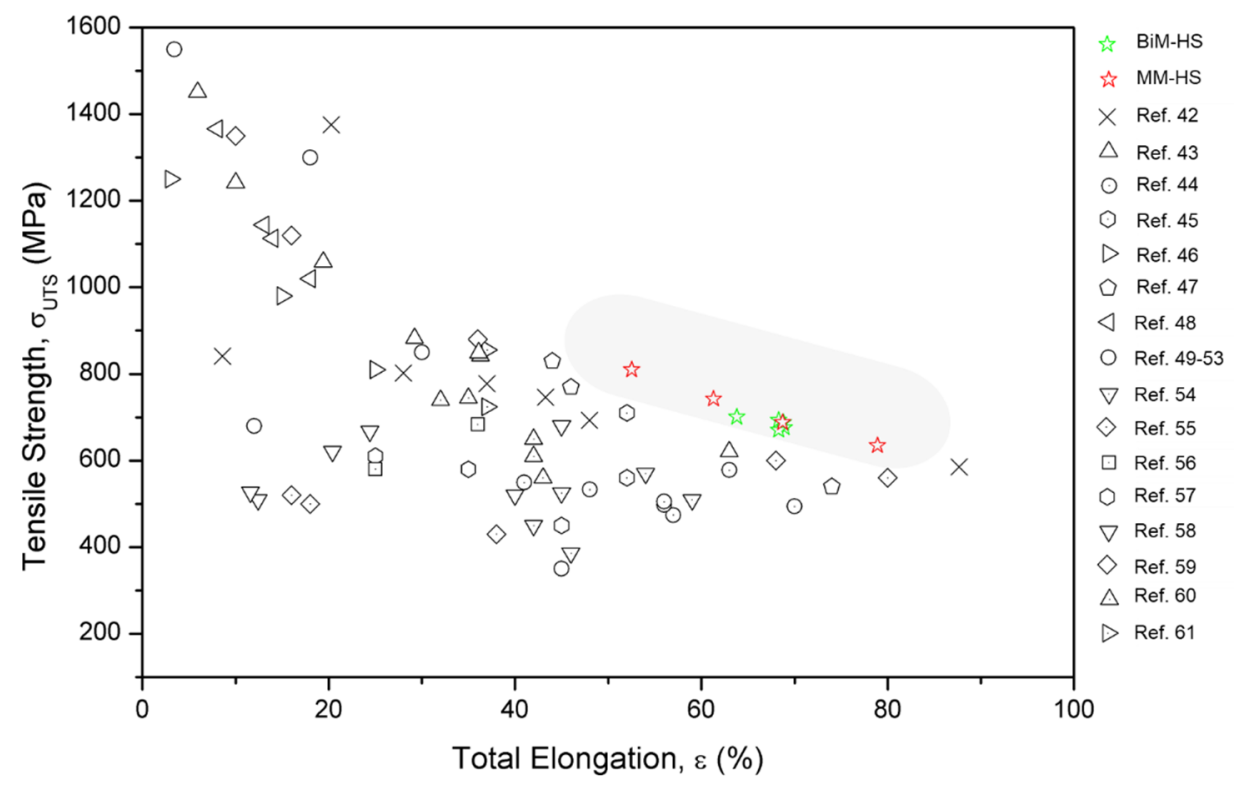

Figure 8. Ultimate tensile strength versus total elongation chart for HS SUS316L compacts, and their comparison with SUS316L counterparts produced by various methods [42-61].

\section{Mechanism of the Outstanding Mechanical Properties}

\subsection{Stress Concentration Effects}

Figure 9 shows the microstructure of conventional homogeneous-structured (homo) and harmonic-structured pure Ti compacts after 10\% cold rolling. EBSD Kernel Average Misorientation (KAM) images show that, in contrast to the homo Ti with significant KAM values in the matrix, slight KAM value increased especially in the shell region. Since the increase in the KAM value strongly related to the dislocation storage, it suggests that deformation took place in the shell and shell/core interface regions.
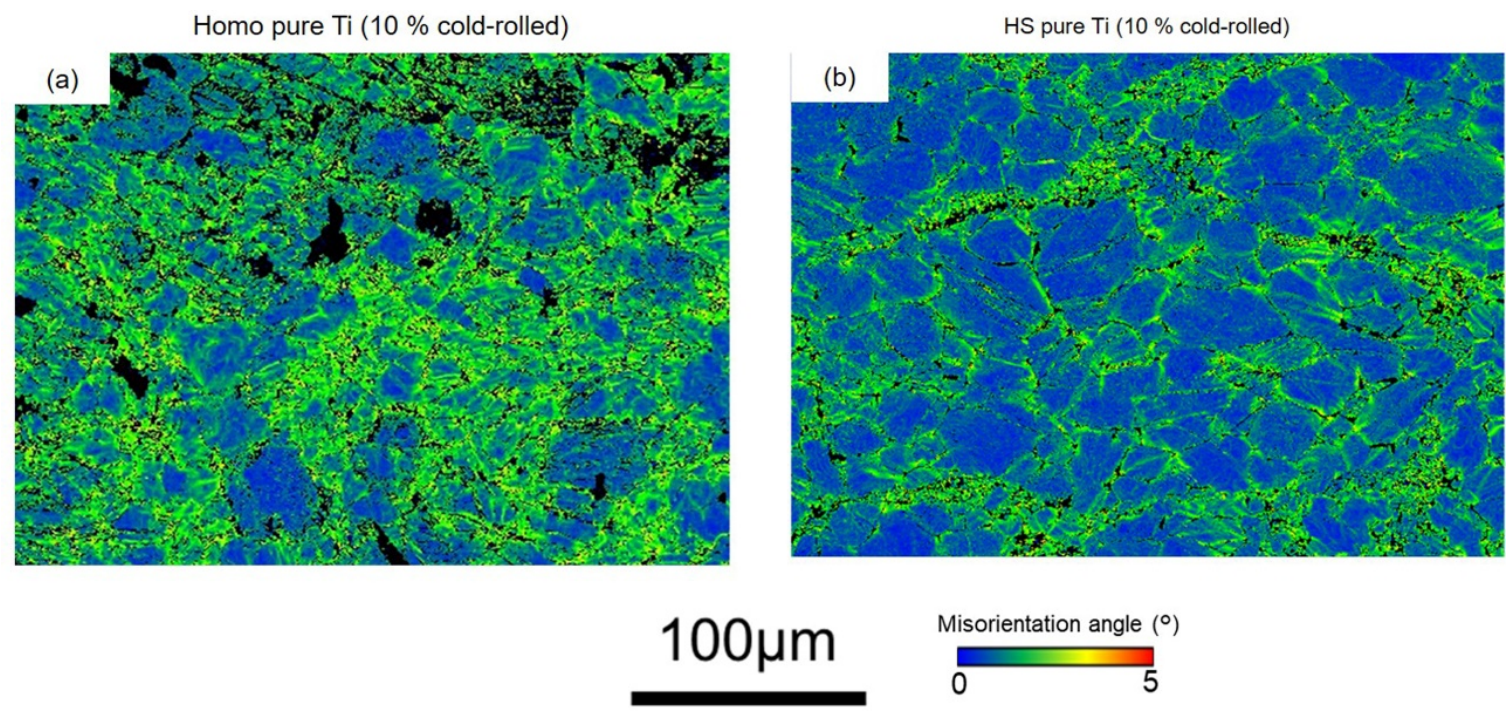

Figure 9. KAM image of; (a) homo and (b) HS structured pure Ti compacts.

As reported by Ameyama et al. [35] using ECCI (Electron Channeling Contrast Image) of Figure 10a: shell area and Figure 10b core area, it can be seen that dislocations were mainly in the shell grains, whereas the core dislocations were cell-like, and comparatively not highly dense 
(Figure 10). These results were quite consistent with the KAM distribution observed for pure Ti (Figure 9). The higher dislocation density in the shell region was evidence of stress concentration in the shell. Therefore, it was confirmed that during the early stage of deformation, the shell and its network can be an effective dislocation source. It is to be noted that such a "dislocation-source network" structure is a unique characteristic of the HS materials. Consequently, a large strain hardening rate and higher uniform elongation can be achieved in the HS materials. Interestingly, despite the soft core regions, the hard shell deforms before the core in the early stage of deformation. Such a stress concentration effect was also predicted by a multi-scale-FEM simulation (Figure 11) [62]. From the numerical simulation, the UFG shell regions are the high-stress concentration areas, while the CG core region did not show evidence of accumulation of any significant stress concentration.
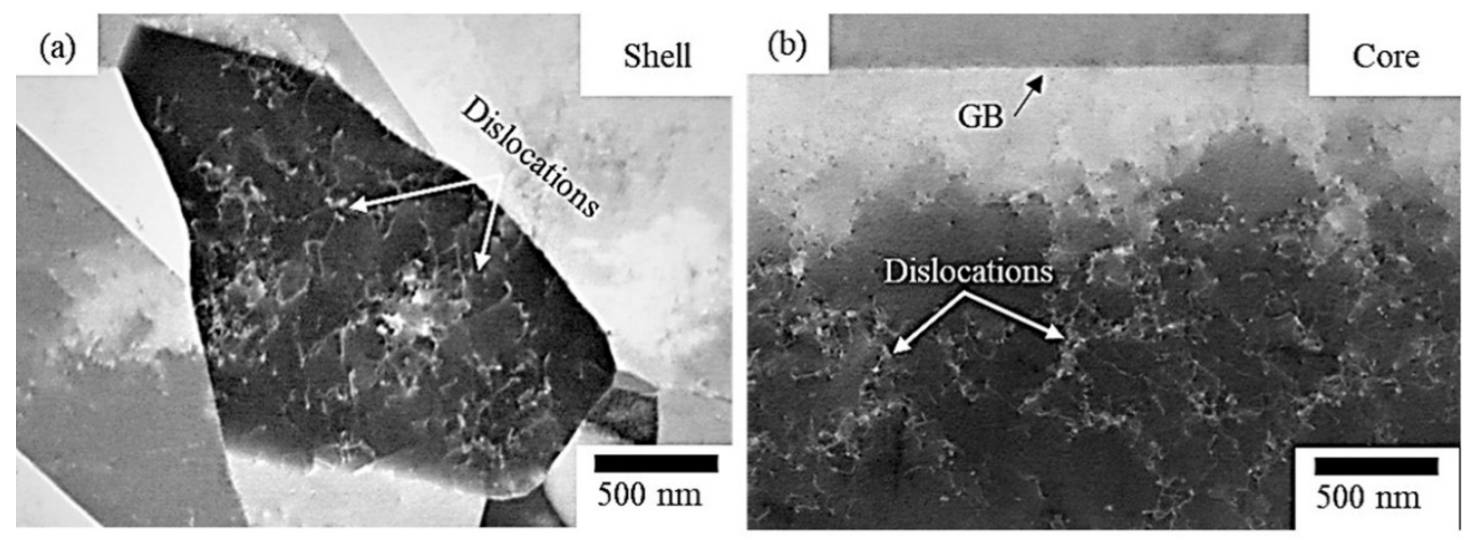

Figure 10. ECCI of pure Ni HS after 5\% tensile deformation. (a): shell and (b): core.

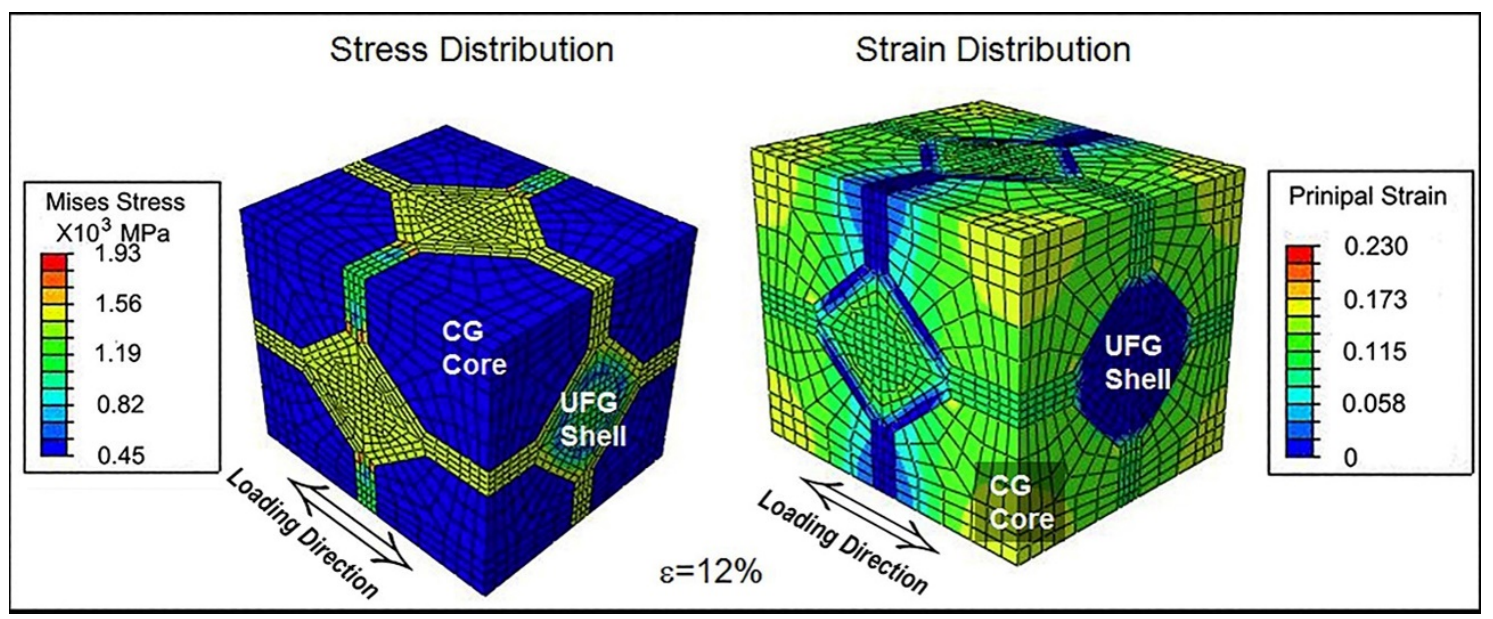

Figure 11. Numerical simulation (FEM) results of HS pure Ti illustrating the stress and strain distribution after $\sim 12 \%$ tensile deformation [62].

\subsection{Strain Dispersion Effects}

It was also reported that the mutual constraints of the unstable UFG area and the comparatively stable CG area made the deformation processing captive and lead to a different stress level [63]. The geometrically necessary dislocations (GNDs) emerged due to the geometrical constraints of soft (core) and hard (shell) areas in the HS specimens' need to accommodate the strain gradient areas; if not, the voids and overlaps may occur between the grain boundaries [64]. As a consequence of the interaction and amassing of dislocations, extraordinary work hardening occurs.

As shown in the numerical simulation results of strain distribution (Figure 11), higher strain concentration was seen in the shell zones aligned parallel to the tensile axis. In contrast, no evidence 
of accumulated strain concentration was seen in the shell zones aligned perpendicular to the tensile deformation axis [62]. However, interestingly, accumulated strain concentration successively increased from the shell to core. Consecutively, the highest accumulated strain was observed at the center of the core.

In general, the early necking of fine-grained materials is due to high-stress concentration. The crack propagation is hard to block with fine grains owing to suppressed dislocation initiation and slip phenomenon $[1,65]$. However, when the well-bonded, tri-directional network of hierarchical microstructure was stressed, the fast strain localization tendency of the fine-grained shell can be effectively constrained by the stable coarse-grained core through the interfaces [66]. In addition, the strain partitioning between incompatible shell and core areas may also play a crucial role in alleviating the strain localization $[62,67,68]$. Such behavior may suggest that the complete shell network structure plays a crucial role in the uniform strain dispersion, and thus, deformation localization is prevented.

\section{Fracture Behavior of HS Materials}

The superior strength-ductility combination of pure HS materials can be attributed to the three-dimensional topological distribution of connected-type hard shell regions. In particular, the higher toughness can be associated with topology-driven diversion of crack propagation paths as well as an obstacle in their growth and propagation due to the soft core regions [69]. To analyze the fatigue crack propagation and growth mechanism, Kikuchi et al. [70] and Osaki et al. [71] investigated the effect of grain size on fatigue crack propagation in HS pure Ti. It was reported that the fatigue crack propagation and growth resistance of HS Ti were significantly reduced for a high-stress ratio as compared to the counterpart with homogeneous coarse-grained microstructure. Nukui et al. [72] found that the fatigue strength is increased because the resistance of the material to the initiation of fatigue cracks was improved by the grain refinement at the shell. The beginning of fatigue cracks was also observed in the coarse grains core in harmonic-structured designed materials, including $\mathrm{CP}$ titanium [72], Ti-6Al-4V alloys $[73,74]$, and austenitic stainless steel $[75,76]$. However, in alloys, it can be attributed to both the network topology and strain-induced phase transformations, for example; $\alpha$-fcc to $\varepsilon$-hcp in CCM [28]. However, further exhaustive studies should be carried out to confirm the fracture behavior of different metallic materials.

\section{Perspectives of HS Materials and Future Challenges}

Harmonic structure-designed materials are emerging structural materials that are becoming an attractive research field. The area of hetero-structured materials was extensively studied. However, in particular, harmonic structure-designed materials are in their infancy, requiring intense studies both in terms of characterization methods, scientific modeling tools, and fabrication approaches.

A complete clarification of the underlying mechanism and availability of any consolidated model regarding the excellent strengthening of HS materials is still a matter of pursuit. Some efforts were made to annotate this direction through experimental documentation as well as theoretical techniques [77-80]. In particular, owing to the unique 3D connected type microstructural design of harmonic-structured materials, rigorous efforts are required to decipher the mechanism of strengthening completely.

In addition, it should be mentioned that development and microstructure controlling of all the customized microstructures, including harmonic structure, are relatively laborious to produce and are not comprehensive. The microstructure control at micro- as well as macro-scale and repeatability in performances are another great challenge. To this aspect, further efforts are required to develop a consolidated design concept and mechanistic approach for harmonic structure-designed materials.

The technological and engineering affairs need to be addressed by both theoretical models and experiments to quantify the correlation between structural heterogeneity and mechanical performance, which is crucial for the development of harmonic structure materials with efficient design and optimized mechanical performance. 


\section{Conclusions}

In this review, a relatively new concept of harmonic structure materials has been introduced, and its basic concept, mechanical performance, and advantages along with present development status and perspectives are discussed. The harmonic structure (HS)-designed metallic materials can be successfully produced by efficient powder metallurgy approaches, such as mechanical milling and bimodal milling (BiM). In contrast to the significant strength-ductility trade-off issues of conventional homogeneous-structured materials, harmonic-structured materials exhibit a superior combination of high synergetic strength and ductility. The superior tensile strength of the HS materials is owing to its unique network-type arrangement of the UFG grains (shell), which provides higher strain hardening due to the stress concentration effect, whereas the superior ductility of the HS materials is attributed to the soft core regions. The results suggested that the higher ductility of the HS materials was due to strain dispersion effects. In other words, microstructural singularity in harmonic structure design plays a crucial role in achieving an outstanding combination of strength and ductility.

Author Contributions: Conceptualization, B.S., G.D., K.A.; methodology, B.S.; formal analysis, B.S.; investigation, B.S.; writing—original draft preparation, B.S.; writing—review and editing, B.S., G.D., K.A.; supervision, K.A.; project administration, B.S., G.D., K.A.; funding acquisition, B.S., G.D., K.A. All authors have read and agreed to the published version of the manuscript.

Funding: This work was supported by the Japan Society for The Promotion of Science (JSPS) Grants-in-Aid for Scientific Research (KAKENHI) Grant Numbers 20K15064 and JP18H05256. This support is gratefully appreciated. The support by the French National Research Agency in the framework of the ANR 14-CE07-0003 "HighS-Ti" program is highly acknowledged.

Conflicts of Interest: The authors declare no conflict of interest.

\section{References}

1. Meyers, M.A.; Mishra, A.; Benson, D.J. Mechanical properties of nanocrystalline materials. Prog. Mater. Sci. 2006, 51, 427-556. [CrossRef]

2. Khan, H.; Farrokh, B.; Takacs, L. Compressive properties of $\mathrm{Cu}$ with different grain sizes: Sub-micron to nanometer realm. J. Mater. Sci. 2008, 43, 3305-3313. [CrossRef]

3. Ma, E.; Zhu, T. Towards strength-Ductility synergy through the design of heterogeneous nanostructures in metals. Mater. Today 2017, 20, 323-331. [CrossRef]

4. Saito, Y.; Utsunomiya, H.; Tsuji, N.; Sakai, T. Novel ultra-high straining process for bulk materials-Development of the accumulative roll-bonding (ARB) process. Acta Mater. 1999, 47, 579-583. [CrossRef]

5. Estrin, Y.; Vinogradov, A. Extreme grain refinement by severe plastic deformation: A wealth of challenging science. Acta Mater. 2013, 61, 782-817. [CrossRef]

6. Manzoni, A.M.; Glatzel, U. New multiphase compositionally complex alloys driven by the high entropy alloy approach. Mater. Charact. 2019, 147, 512-532. [CrossRef]

7. Kumar, K.; Van Swygenhoven, H.; Suresh, S. Mechanical behavior of nanocrystalline metals and alloys11The Golden Jubilee Issue-Selected topics in Materials Science and Engineering: Past, Present and Future, edited by S. Suresh. Acta Mater. 2003, 51, 5743-5774. [CrossRef]

8. Zhao, Y.H.; Lavernia, E.J.; Whang, S.H. Nanostructured Metals and Alloys; Woodhead Publishing: Cambridge, UK, 2011; pp. 375-376.

9. Hofinger, M.; Turk, C.; Ognianov, M.; Leitner, H.; Schnitzer, R. Precipitation reactions in a Cu-Ni-Al medium carbon alloyed dual hardening steel. Mater. Charact. 2020, 160, 110126. [CrossRef]

10. Wegst, U.G.K.; Bai, H.; Saiz, E.; Tomsia, A.P.; Ritchie, R.O. Bioinspired structural materials. Nat. Mater. 2015, 14, 23-36. [CrossRef]

11. Gwalani, B.; Soni, V.; Lee, M.; Mantri, S.; Ren, Y.; Banerjee, R. Optimizing the coupled effects of Hall-Petch and precipitation strengthening in a Al $0.3 \mathrm{CoCrFeNi}$ high entropy alloy. Mater. Des. 2017, 121, 254-260. [CrossRef] 
12. Cheng, H.; Wang, H.Y.; Xie, Y.C.; Tang, Q.H.; Dai, P.Q. Controllable fabrication of a carbide-containing FeCoCrNiMn high-entropy alloy: Microstructure and mechanical properties. Mater. Sci. Technol. 2017, 33, 2032-2039. [CrossRef]

13. Wu, X.; Yang, M.; Yuan, F.; Wu, G.; Wei, Y.; Huang, X.; Zhu, Y. Heterogeneous lamella structure unites ultrafine-grain strength with coarse-grain ductility. Proc. Natl. Acad. Sci. USA 2015, 112, 14501-14505. [CrossRef] [PubMed]

14. Embury, D.; Bouaziz, O. Steel-based composites: Diving forces and Classifications. Annu. Rev. Mater. Res. 2010, 40, 213-241. [CrossRef]

15. Wu, X.; Zhu, Y.T. Heterogeneous materials: A new class of materials with unprecedented mechanical properties. Mater. Res. Lett. 2017, 5, 527-532. [CrossRef]

16. Lu, K. Stabilizing nanostructures in metals using grain and twin boundary architectures. Nat. Rev. Mater. 2016, 1, 16019. [CrossRef]

17. Wang, Y.; Chen, M.; Zhou, F.; Ma, E. High tensile ductility in a nanostructured metal. Nat. Cell Biol. 2002, 419, 912-915. [CrossRef]

18. Fang, T.H.; Li, W.L.; Tao, N.R.; Lu, K. Revealing Extraordinary Intrinsic Tensile Plasticity in Gradient Nano-Grained Copper. Science 2011, 331, 1587-1590. [CrossRef]

19. Wu, X.; Jiang, P.; Chen, L.; Yuan, F.; Zhu, Y.T. Extraordinary strain hardening by gradient structure. Proc. Natl. Acad. Sci. USA 2014, 111, 7197-7201. [CrossRef]

20. Thevamaran, R.; Lawal, O.; Yazdi, S.; Jeon, S.-J.; Lee, J.-H.; Thomas, E.L. Dynamic creation and evolution of gradient nanostructure in single-crystal metallic microcubes. Science 2016, 354, 312-316. [CrossRef]

21. Cheng, Z.; Zhou, H.; Lu, Q.; Gao, H.; Lu, L. Extra strengthening and work hardening in gradient nanotwinned metals. Science 2018, 362, eaau1925. [CrossRef]

22. Liu, X.C.; Zhang, H.; Lu, K. Strain-Induced Ultrahard and Ultrastable Nanolaminated Structure in Nickel. Science 2013, 342, 337-340. [CrossRef] [PubMed]

23. Zhang, Z.; Vajpai, S.K.; Orlov, D.; Ameyama, K. Improvement of mechanical properties in SUS304L steel through the control of bimodal microstructure characteristics. Mater. Sci. Eng. A 2014, 598, 106-113. [CrossRef]

24. Vajpai, S.K.; Ota, M.; Watanabe, T.; Maeda, R.; Sekiguchi, T.; Kusaka, T.; Ameyama, K. The Development of High Performance Ti-6Al-4V Alloy via a Unique Microstructural Design with Bimodal Grain Size Distribution. Met. Mater. Trans. A 2015, 46, 903-914. [CrossRef]

25. Sharma, B.; Nagano, K.; Kawabata, M.; Ameyama, K. Microstructure and mechanical properties of hetero-designed Ti-25Nb-25Zr alloy fabricated by powder metallurgy route. Lett. Mater. 2019, 9, 511-516. [CrossRef]

26. Ota, M.; Vajpai, S.K.; Imao, R.; Kurokawa, K.; Ameyama, K. Application of High Pressure Gas Jet Mill Process to Fabricate High Performance Harmonic Structure Designed Pure Titanium. Mater. Trans. 2015, 56, 154-159. [CrossRef]

27. Vajpai, S.K.; Ota, M.; Zhang, Z.; Ameyama, K. Three-dimensionally gradient harmonic structure design: An integrated approach for high performance structural materials. Mater. Res. Lett. 2016, 4, 191-197. [CrossRef]

28. Vajpai, S.K.; Sawangrat, C.; Yamaguchi, O.; Ciuca, O.P.; Ameyama, K. Effect of bimodal harmonic structure design on the deformation behavior and mechanical properties of Co-Cr-Mo alloy. Mater. Sci. Eng. C 2016, 58, 1008-1015. [CrossRef]

29. Fujiwara, H.; Oda, E.; Ameyama, K. Mechanical Milling Process as Severe Plastic Deformation Method. Tetsu-to-Hagane 2008, 94, 608-615. [CrossRef]

30. Ameyama, K.; Horikawa, N.; Kawabata, M. Unique Mechanical Properties of Harmonic Structure Designed Materials. Tetsu-to-Hagane 2019, 105, 124-126. [CrossRef]

31. Fujiwara, H.; Inomoto, H.; Sanada, R.; Ameyama, K. Nano-ferrite formation and strain-induced-ferrite transformation in an SUS316L austenitic stainless steel. Scr. Mater. 2001, 44, 2039-2042. [CrossRef]

32. Yagi, K.; Sharma, B.; Kawabata, M.; Ameyama, K. Fabrication of SUS316L Harmonic Structure Compacts by Bi-Modal Milling Process. J. Jpn. Soc. Powder Powder Met. 2020, 67, 239-244. [CrossRef]

33. Nagata, M.; Horikawa, N.; Kawabata, M.; Ameyama, K. Effects of Microstructure on Mechanical Properties of Harmonic Structure Designed Pure Ni. Mater. Trans. 2019, 60, 1914-1920. [CrossRef]

34. Sawangrat, C.; Yamaguchi, O.; Vajpai, S.K.; Ameyama, K. Application of Harmonic Structure Design to Biomedical Co-Cr-Mo Alloy for Improved Mechanical Properties. Mater. Trans. 2014, 55, 99-105. [CrossRef] 
35. Ameyama, K.; Kawabata, M.; Sharma, B. ISOPE-I-19-101. In Proceedings of the 29th International Ocean and Polar Engineering Conference, Honolulu, HI, USA, 16-21 June 2019; ISBN 978-1-880653-85-2.

36. Sawangrat, C.; Kato, S.; Orlov, D.; Ameyama, K. Harmonic-structured copper: Performance and proof of fabrication concept based on severe plastic deformation of powders. J. Mater. Sci. 2014, 49, 6579-6585. [CrossRef]

37. Fujiwara, H.; Akada, R.; Noro, A.; Yoshita, Y.; Ameyama, K. Enhanced Mechanical Properties of Nano/Meso Hybrid Structure Materials Produced by Hot Roll Sintering Process. Mater. Trans. 2008, 49, 90-96. [CrossRef]

38. Fujiwara, H.; Inomoto, H.; Ameyama, K. Formation of $(\alpha+\gamma)$ Nano-duplex Structure by Severe Plastic Deformation in an SUS316L Stainless Steel. Tetsu-to-Hagane 2005, 91, 839-845. [CrossRef]

39. Mohamed, F.A. A dislocation model for the minimum grain size obtainable by milling. Acta Mater. 2003, 51, 4107-4119. [CrossRef]

40. Chaubey, A.K.; Scudino, S.; Khoshkhoo, M.S.; Prashanth, K.G.; Mukhopadhyay, N.K.; Mishra, B.; Eckert, J. Synthesis and Characterization of NanocrystallineMg-7.4\%Al Powders Produced by Mechanical Alloying. Metals 2013, 3, 58-68. [CrossRef]

41. Oda, E.; Fujiwara, H.; Ameyama, K. Nano Grain Formation in Tungsten by Severe Plastic Deformation-Mechanical Milling Process. Mater. Trans. 2008, 49, 54-57. [CrossRef]

42. Zheng, R.; Zhang, Z.; Nakatani, M.; Ota, M.; Chen, X.; Ma, C.; Ameyama, K. Enhanced ductility in harmonic structure designed SUS316L produced by high energy ball milling and hot isostatic sintering. Mater. Sci. Eng. A 2016, 674, 212-220. [CrossRef]

43. Li, J.; Cao, Y.; Gao, B.; Li, Y.; Zhu, Y.T. Superior strength and ductility of 316L stainless steel with heterogeneous lamella structure. J. Mater. Sci. 2018, 53, 10442-10456. [CrossRef]

44. Chen, X.; Li, J.; Cheng, X.; Wang, H.; Huang, Z. Effect of heat treatment on microstructure, mechanical and corrosion properties of austenitic stainless steel 316L using arc additive manufacturing. Mater. Sci. Eng. A 2018, 715, 307-314. [CrossRef]

45. Yin, Y.; Sun, J.; Guo, J.; Kan, X.; Yang, D. Mechanism of high yield strength and yield ratio of 316 L stainless steel by additive manufacturing. Mater. Sci. Eng. A 2019, 744, 773-777. [CrossRef]

46. Long, Q.; Lu, J.; Fang, T. Microstructure and mechanical properties of AISI 316L steel with an inverse gradient nanostructure fabricated by electro-magnetic induction heating. Mater. Sci. Eng. A 2019, 751, 42-50. [CrossRef]

47. Lu, K.; Yan, F.; Wang, H.; Tao, N. Strengthening austenitic steels by using nanotwinned austenitic grains. Scr. Mater. 2012, 66, 878-883. [CrossRef]

48. Xiong, L.; You, Z.; Lu, L. Enhancing fracture toughness of nanotwinned austenitic steel by thermal annealing. Scr. Mater. 2016, 119, 55-59. [CrossRef]

49. Chen, X.; Lu, J.; Lu, L.; Lu, K. Tensile properties of a nanocrystalline 316L austenitic stainless steel. Scr. Mater. 2005, 52, 1039-1044. [CrossRef]

50. Wang, Y.; Huang, C.; Wang, M.; Li, Y.; Zhu, Y. Quantifying the synergetic strengthening in gradient material. Scr. Mater. 2018, 150, 22-25. [CrossRef]

51. Ueno, H.; Kakihata, K.; Kaneko, Y.; Hashimoto, S.; Vinogradov, A. Enhanced fatigue properties of nanostructured austenitic SUS 316L stainless steel. Acta Mater. 2011, 59, 7060-7069. [CrossRef]

52. Poling, W.A. Grain Size Effects in Micro-Tensile Testing of Austenitic Stainless Steel. Master's Thesis, Colorado School of Mines, Golden, CO, USA, 2012.

53. Vinogradov, A.; Yasnikov, I.; Matsuyama, H.; Uchida, M.; Kaneko, Y.; Estrin, Y. Controlling strength and ductility: Dislocation-based model of necking instability and its verification for ultrafine grain 316L steel. Acta Mater. 2016, 106, 295-303. [CrossRef]

54. Zhong, Y.; Rannar, L.E.; Liu, L.; Koptyug, A.; Wikman, S.; Olsen, J.; Cui, D.; Shen, Z. Additive manufacturing of 316L stainless steel by electron beam melting for nuclear fusion applications. J. Nucl. Mater. 2017, 486, 234-245. [CrossRef]

55. Röttger, A.; Geenen, K.; Windmann, M.; Binner, F.; Theisen, W. Comparison of microstructure and mechanical properties of 316L austenitic steel processed by selective laser melting with hot-isostatic pressed and cast material. Mater. Sci. Eng. A 2016, 678, 365-376. [CrossRef]

56. Casati, R.; Lemke, J.; Vedani, M. Microstructure and Fracture Behavior of 316L Austenitic Stainless Steel Produced by Selective Laser Melting. J. Mater. Sci. Technol. 2016, 32, 738-744. [CrossRef] 
57. Bartolomeu, F.; Buciumeanu, M.; Pinto, E.; Alves, N.; Carvalho, O.; Silva, F.; Miranda, G. 316L stainless steel mechanical and tribological behavior-A comparison between selective laser melting, hot pressing and conventional casting. Addit. Manuf. 2017, 16, 81-89. [CrossRef]

58. Suryawanshi, J.; Prashanth, K.; Ramamurty, U. Mechanical behavior of selective laser melted 316L stainless steel. Mater. Sci. Eng. A 2017, 696, 113-121. [CrossRef]

59. Wang, S.; Li, J.; Cao, Y.; Gao, B.; Mao, Q.; Li, Y. Thermal stability and tensile property of 316L stainless steel with heterogeneous lamella structure. Vacuum 2018, 152, 261-264. [CrossRef]

60. Ma, M.; Wang, Z.; Zeng, X. A comparison on metallurgical behaviors of 316L stainless steel by selective laser melting and laser cladding deposition. Mater. Sci. Eng. A 2017, 685, 265-273. [CrossRef]

61. Peng, P.; Wang, K.-S.; Wang, W.; Han, P.; Zhang, T.; Liu, Q.; Zhang, S.; Wang, H.; Qiao, K.; Liu, J. Relationship between microstructure and mechanical properties of friction stir processed AISI 316L steel produced by selective laser melting. Mater. Charact. 2020, 163, 110283. [CrossRef]

62. Vajpai, S.K.; Yu, H.; Ota, M.; Watanabe, I.; Dirras, G.; Ameyama, K. Three-Dimensionally Gradient and Periodic Harmonic Structure for High Performance Advanced Structural Materials. Mater. Trans. 2016, 57, 1424-1432. [CrossRef]

63. Yang, X.; Zhang, J.; Gong, Y.; Nakatani, M.; Sharma, B.; Ameyama, K.; Zhu, X. A superior strength-ductility combination in gradient structured $\mathrm{Cu}-\mathrm{Al}-\mathrm{Zn}$ alloys with proper stacking fault energy and processing time. Mater. Sci. Eng. A 2020, 789, 139619. [CrossRef]

64. Kundu, A.; Field, D.P. Influence of plastic deformation heterogeneity on development of geometrically necessary dislocation density in dual phase steel. Mater. Sci. Eng. A 2016, 667, 435-443. [CrossRef]

65. Yang, M.; Pan, Y.; Yuan, F.; Zhu, Y.; Wu, X. Back stress strengthening and strain hardening in gradient structure. Mater. Res. Lett. 2016, 4, 145-151. [CrossRef]

66. Lu, K. Making strong nanomaterials ductile with gradients. Science 2014, 345, 1455-1456. [CrossRef] [PubMed]

67. Zheng, R.; Liu, M.; Zhang, Z.; Ameyama, K.; Ma, C. Towards strength-ductility synergy through hierarchical microstructure design in an austenitic stainless steel. Scr. Mater. 2019, 169, 76-81. [CrossRef]

68. Fan, G.; Geng, L.; Wu, H.; Miao, K.; Cui, X.; Kang, H.; Wang, T.; Xie, H.; Xiao, T. Improving the tensile ductility of metal matrix composites by laminated structure: A coupled X-ray tomography and digital image correlation study. Scr. Mater. 2017, 135, 63-67. [CrossRef]

69. Ueno, A.; Fujiwara, H.; Rifai, M.; Zhang, Z.; Ameyama, K. Fractographical Analysis on Fracture Mechanism of Stainless Steel Having Harmonic Microstructure. J. Soc. Mater. Sci. Jpn. 2012, 61, 686-691. [CrossRef]

70. Kikuchi, S.; Mori, T.; Kubozono, H.; Nakai, Y.; Kawabata, M.O.; Ameyama, K. Evaluation of near-threshold fatigue crack propagation in harmonic-structured $\mathrm{CP}$ titanium with a bimodal grain size distribution. Eng. Fract. Mech. 2017, 181, 77-86. [CrossRef]

71. Osaki, K.; Kikuchi, S.; Nakai, Y.; Kawabata, M.O.; Ameyama, K. The effects of thermo-mechanical processing on fatigue crack propagation in commercially pure titanium with a harmonic structure. Mater. Sci. Eng. A 2020, 773, 138892. [CrossRef]

72. Nukui, Y.; Kubozono, H.; Kikuchi, S.; Nakai, Y.; Ueno, A.; Kawabata, M.O.; Ameyama, K. Fractographic analysis of fatigue crack initiation and propagation in $\mathrm{CP}$ titanium with a bimodal harmonic structure. Mater. Sci. Eng. A 2018, 716, 228-234. [CrossRef]

73. Kikuchi, S.; Takemura, K.; Ueno, A.; Ameyama, K. Evaluation of the 4-points bending fatigue properties of Ti-6Al-4V alloy with harmonic structure created by mechanical milling and spark plasma sintering. J. Soc. Mater. Sci. Jpn. 2015, 64, 880-886. [CrossRef]

74. Kikuchi, S.; Kubozono, H.; Nukui, Y.; Nakai, Y.; Ueno, A.; Kawabata, M.O.; Ameyama, K. Statistical fatigue properties and small fatigue crack propagation in bimodal harmonic structured Ti-6Al-4V alloy under four-point bending. Mater. Sci. Eng. A 2018, 711, 29-36. [CrossRef]

75. Kikuchi, S.; Nakatsuka, Y.; Nakai, Y.; Nakatani, M.; Kawabata, M.O.; Ameyama, K. Evaluation of Fatigue Properties under Four-point Bending and Fatigue Crack Propagation in Austenitic Stainless Steel with a Bimodal Harmonic Structure. Frattura ed Integrità Strutturale 2019, 13, 545-553. [CrossRef]

76. Kikuchi, S.; Nukui, Y.; Nakatsuka, Y.; Nakai, Y.; Nakatani, M.; Kawabata, M.O.; Ameyama, K. Effect of bimodal harmonic structure on fatigue properties of austenitic stainless steel under axial loading. Int. J. Fatigue 2019, 127, 222-228. [CrossRef] 
77. Wang, X.; Cazes, F.; Li, J.; Hocini, A.; Ameyama, K.; Dirras, G. A 3D crystal plasticity model of monotonic and cyclic simple shear deformation for commercial-purity polycrystalline Ti with a harmonic structure. Mech. Mater. 2019, 128, 117-128. [CrossRef]

78. Liu, J.; Dirras, G.; Ameyama, K.; Cazes, F.; Ota, M. A three-dimensional multi-scale polycrystalline plasticity model coupled with damage for pure Ti with harmonic structure design. Int. J. Plast. 2018, 100, 192-207. [CrossRef]

79. Dirras, G.; Tingaud, D.; Ueda, D.; Hocini, A.; Ameyama, K. Dynamic Hall-Petch versus grain-size gradient effects on the mechanical behavior under simple shear loading of $\beta$-titanium Ti-25Nb-25Zr alloys. Mater. Lett. 2017, 206, 214-216. [CrossRef]

80. Mompiou, F.; Tingaud, D.; Chang, Y.; Gault, B.; Dirras, G. Conventional vs. harmonic-structured $\beta$-Ti-25Nb-25Zr alloys: A comparative study of deformation mechanisms. Acta Mater. 2018, 161, 420-430. [CrossRef]

Publisher's Note: MDPI stays neutral with regard to jurisdictional claims in published maps and institutional affiliations.

(C) 2020 by the authors. Licensee MDPI, Basel, Switzerland. This article is an open access article distributed under the terms and conditions of the Creative Commons Attribution (CC BY) license (http://creativecommons.org/licenses/by/4.0/). 